\title{
Green Dentistry: Eco-friendly Dentistry
}

Shailee Fotedar ${ }^{1}$

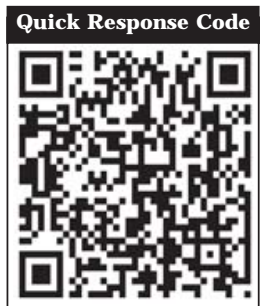

doi: $10.5866 / 2014.641703$

${ }^{1}$ H.P Govt. Dental College Shimla, India

\section{Article Info:}

Received: J uly 10, 2014

Review Completed: August 11, 2014

Accepted: November 10, 2014

Available Online: J anuary, 2015 (www.nacd.in) (C) NAD, 2015 - All rights reserved

\section{Email for correspondence:}

drfotedar@rediffmail.com

\begin{abstract}
:
Climate change and environment are important global issues, which every one of us should be concerned and aware of. Traditional dentistry produces wastematerials that cause harm to the soil and to the biosphere. So it is the need of the hour what every one of us in the dental profession can do our bit to protect our planet. The present review focuses on some of the ways a dental professional can follow and makea hugedifference in the long run.
\end{abstract}

Key words: Green dentistry.

\section{Introduction:}

The earth is gradually going to its destruction because of the neglect of man. Substances used for the benefit of humankind are often harmful to the environment. Traditional dentistry produces waste materials that are very hard to dispose of. There are toxic dental materials causing harm to the soil and to the biosphere. To reduce the damage created by these gradually going to its destruction waste products, the field of dentistry found ways to make dental practices more eco-friendly. ${ }^{1}$ Being responsible professionals, it is our obligation to our patients and our planet to take every possible measure to help protect our environment, our resources, and our neighbours, This is possible only by means of ecofriendly dental practices or "green dentistry" "Green dentistry" is a vast topic that touches on everything from patient care to dental processes. Green dentistry is a high-tech approach that reduces the environmental impact of dental practices and encompasses a service model for dentistry that supports and maintains wellness. ${ }^{2}$

E co dentistry or "green dentistry" refers to the delivery of oral health care and dental treatments using technologies, procedures and materials that promote environmental and planetary health. Ecodentistry, a term trademarked by the E co-Dentistry (EDA), incorporates high tech innovations that enhance efficiency and effectiveness while reducing the amount of waste and pollution in the technologies, procedures and materials. ${ }^{3}$

\section{Advantages of Green dentistry:}

1. Reduces waste and pollution 
2. Saves energy, water and money

3. Uses high-tech practices.

4. Supports a wellness lifestyle, focusing on preventative care and lifelong dental and whole body health.

How to green our dental practice: Some ways of greening our dental practice:

Use digital X-rays: one of the most significant innovations for green dental practices is digital radiography, which eliminates the need for traditional film X-ray systems. With digital X-rays, dental practices dramatically reduce the harmful chemicals such as lead and silver that are released into the environment. Additionally, patients are exposed to approximately 90 percent less radiation with digital imaging compared to traditional X-rays. Also, images are available to your dentist immediately and are of better quality than traditional X-rays and can be enlarged for greater diagnostic detail and accuracy. ${ }^{4}$

Go paperless: By switching to digital patient files and billing, we can increase staff efficiency and reduce the material costs of folders, labels, and preprinted forms. We can also try using electronic forms on which patients can enter information. When paper cannot be avoided, use recycled paper products.

Install an amalgam separator: Amalgam separators pull the mercury out of your vacuum waste and prevent it from going down the drain and contaminating your waste water or the water bodies in your area. ${ }^{4}$

Go for less Chemical Contamination and Fewer Disposables: Green dental practices also use high-quality, biodegradable disinfectants and steam sterilization methods that don't require ventilation for chemical vapors, or a hazardous waste permit for disposal of toxic chemicals into a watersupply. ${ }^{5}$

Go for more Natural-looking Restorations. Less Heavy Metal Waste: As today we may be interested in more natural looking restorations, ecodentistry embraces today's adhesive, metal-free dental restoratives like direct composite bonding or porcelain veneers and crowns. These options serve two purposes: First, they provide metal-free, esthetic smile treatments. Secondly, they hel p eliminate the heavy metal waste associated with silver amalgam fillings that could end up in the main water supply.

Reduce water usage: Most people don't realize that water purification plants and wastewater treatment plants consume a great deal of energy, use large quantities of materials, and create much waste. There are many ways in which dental clinics can reduce both water consumption and wastewater output. Water is wasted by letting it run when doing something and leaving it running while they dry their hands instead of turning it off. So it's important to turn the water off when it is not in use. To remind everyone, it is good to put a sign at each sink in the office which says" Please turn off the water when not in use". Steam-based sterilization equipment uses less water. ${ }^{5}$

Reduce waste: When we reduce our waste, we reduce overhead costs, save valuable materials, and minimize impact on landfills.Some of the ways are

- Switch to cloth sterilization bags and patient barriers.

- Wear cloth lab coats instead of paper ones.

- Use re-usable face shields.

- Re-use lab and shipping boxes.

- Switch to stainless steel impression trays, suction tips.

- $\quad$ Provide glass or ceramic rinsing cups.

- Use washable dishes and cutlery in the staff break room. ${ }^{6}$

Reduce phantom power: Never forget the devious "vampire power" or "phantom electricity" we use on a daily basis but don't typically think about-the trickles of electricity that drain from certain appliances, transformers, and equipment even when not in use. Devices that use phantom power include electronic phones, surge-protected extension cords, small transformers for electronics, and instant-on devices like TVs, monitors, and computers. The small amounts of electricity these devices use all day and night can add up to quite a bit. Save money by setting up computers, tel evisions, and other equipment so that power is completely 
shut off at night and on weekends. Use compact fluorescent lamps is another way to reduce your monthly electric bill is to replace incandescent light bulbs with compact fluorescent lamps (CFLs). CFLs last several years and use about 75 percent less ectricityDental clinics have additional lighting which is needed for improved vision in the dental surgery but which are left on even if surgery is not there on that day. Switching off lights on lunch breaks and use of energy saving bulbs in reception and communal areas. $^{7}$

Choose new equipment wisely: When it's timeto replace appliances, monitors, and computers, look for equipment with the energy star label. Some energy-efficient devices pay for themselves in just a few years with their reduction in energy use. Don't forget to recycle any old devices you replace! ${ }^{4}$

\section{Ways To Turn The Daily Dental Routine Green}

1. Turn it off: Don't leave the water running while you are brushing. Turn it only to rinse your mouth and brush.

2. Go natural: Natural toothpaste breaks down easier and helps protect our water ways.

3. Compost: Buy a composting (biodegradable) tooth brush. Made from corn starch, these brushes wont clog our landfill and some can even help our garden grow.

4. Soft as a baby's $\mathbf{s}^{1 / 4}$. Don't brush so hard,slow down and be gentle on your gums. It will not only save your gums, it will also make your toothbrush last longer, saving you money and reducing waste.
5. Floss: Flossing most important for your teeth. By flossing prevents dental disease their by saving money and reducing materials used for restoring teeth. ${ }^{8}$

All of these options are easy to access and are economically and financially viable. Simplesteps can be taken to reduce the environmental contamination produced by a dental practice.

\section{References}

1. Green Dentistry: Its Benefits to Health and the Environment. [Online].[cited on 2012 june 15 $5^{\text {th }}$ ]; available from URL: http:// www.articlesbase.com/dental-care-articles/green-dentistry.

2. Susan Beck. What Exactly is Green Dentistry? [Online].[cited on 2012 june 17th ; available from URL: http:// www.friendsofhu-friedy.com.

3. Allison De Matteo. E co-Dentistry: “Green," Environmentally Friendly Dental Care[Online].[cited on 2012 june 20 $2{ }^{\text {th }}$ ]; available from URL: www.yourdentistryguide.com/greendentistry.

4. Robert Shaffer.Keep Your Dental Practice Fresh by Becoming "Green" [Online].[cited on 2012 june 25th ; available from URL: www.foundationar ch.com/pdfs/Foundation_GreenDentistry.pdf.

5. Shetty Vittal das.Green Dentistry. J Ind Assoc Pub Health Dent 2012;18(2):891-93.

6. Shannon Rae Treasure.Green Dentistry for the modern Dentist.[Online].[cited on 2012 J uly $4^{\text {rth }}$ ]; available from URL :ezinearticles.com > Health and Fitness > Dental arehttp:// EzineArticles.com/?expert=Shan.

7. Green Dentistry - Good for you and the earth. [Online].[cited on 2012 July 7th ]; available from URL http:// naturaldentistry.us/holistic-dentistry/green-dentistry.

8. Dr Marvin. The centre for natural dentist. [Online].[cited on 2012 July $8^{\text {th }}$; available from URL http:// nutritionjunki.blogspot.in.

\section{Gain quick access to our journal online View our journal at wWw.nacd.in}

